\title{
URGENSI PROGRAM SERTA KURIKULUM BIMBINGAN DAN KONSELING
}

\author{
Edy Legowo ${ }^{(1)}$, Agus Tri Susilo ${ }^{(2)}$, Ma'rifatin Indah Kholili ${ }^{(3)}$ \\ Program Studi Bimbingan dan Konseling \\ Universitas Sebelas Maret Surakarta \\ E-mail: legowobk@gmail.com
}

\begin{abstract}
Abstrak
Problematika yang dialami praktisi di bidang bimbingan dan konseling selama ini adalah pengembangan program yang masih bersifat konvensional. Perlu dilakukan upaya oleh akademisi untuk memberikan pendampingan agar guru bimbingan dan konseling paham mengenai program yang sesuai dengan kebutuhan siswa. Melalui pemahaman mengenai penyusunan program berbasis kebutuhan (pengembangan kompetensi siswa) maka paradigma bimbingan dan konseling yang hanya bertugas mengatasi masalah siswa dapat diubah. Sudut pandang kedepannya penyusunan program BK berbasis kompetensi bukan berbasih masalah. Harapannya program yang tersusun dapat tepat sasaran dan mengubah mind set mereka melalui kegiatan workshop dan pendampingan pengembangan program BK berbasis standar kompetensi siswa.
\end{abstract}

Kata Kunci : kompetensi siswa, kurikulum, program BK

\begin{abstract}
The problem experienced by practitioners in the field of guidance and counseling so far is the development of programs that are still conventional. Academics should be do action to provide assistance so that the teacher's guidance and counseling understand about the program that suits students' needs. Through an understanding of the needs-based programming (development of student competencies), the guidance and counseling paradigm is only tasked with overcoming student problems can be changed. In the future, the compilation of guidance and counseling programs based on competence not problematic. It is hoped that the structured program can be on target and change their mind sets through workshops and mentoring the development of guidance and counseling programs based on student competency standards.
\end{abstract}

Keywords: student competencies, curriculum, guidance and counseling program,

\section{Info Artikel}

Diterima September 2019, disetujui Oktober 2019, diterbitkan Desember 2019

Dipublikasikan Oleh: Program Studi Bimbingan dan Konseling 


\section{PENDAHULUAN}

Permasalahan yang dialami guru Bimbingan dan Konseling selama ini adalah pengembangan program bimbingan dan konseling masih bersifat konvensional. Program BK konvensional yang dimaksud adalah suatu program BK yang berfokus pada upaya-upaya penanganan masalah siswa. Kondisi ini telah berlangsung puluhan tahun hingga sekarang atau sejak program BK secara formal dicanangkan di sekolah pada tahun 1975 untuk SMP dan tahun 1976 untuk SMA. Tidak terlalu disalahkan, jika sebagian besar anggota masyarakat bahkan para guru dan siswa masih memandang bahwa BK di sekolah tempat menampung dan mengatasi anak-anak bermasalah.

Didukung lagi oleh kondisi dimana para guru BK baik di jenjang pendidikan SMP maupun SMA lebih dalam mengembangkan program lebih menekankan fungsi kuratif. Program BK berorientasi pada fungsi kuratif yaitu program disusun untuk tujuan penanganan masalah siswa melalui kegiatan layanan responsif. Sementara fungsi developmental dan preventif BK yang seharusnya diutamakan, namun tidak menjadi prioritas. Hal ini terjadi karena dasar penyusunan program BK lebih berbasis pada data hasil asesmen tentang masalah-masalah yang dialami para siswa. Instrumen asesmen yang sering digunakan untuk maksud pengembangan program tersebut adalah Alat Ungkap Masalah (AUM) dan Daftar Cek Masalah (DCM).

Jika diperhatikan bahwa sistem pendidikan secara umum bertujuan untuk mengembangkan potensi dan membekali siswa agar dapat berkembang secara optimal baik secara kognitif (akademik), afektif (personal), dan keterampilan. Oleh sebab itu dalam sistem pendidikan di sekolah ada dua program utama yaitu program pembelajaran dan program bimbingan dan konseling (Gysbers dan Henderson, 2012). Program pembelajaran menekankan pada bidang ilmu pengetahuan dasar (mata pelajaran) dan penyiapan pekerjaan bagi siswa, sedangkan program bimbingan dan konseling menekankan pada perkembangan akademik, pribadi-sosial, dan karier siswa.

Pada program pembelajaran, Kementerian Pendidikan dalam hal ini Dirjen Guru dan Tenaga Kependidikan (GTK) telah menyediakan seperangkat kurikulum 2013 untuk penyelenggaraan pendidikan di jenjang SD, SMP, SMA, dan SMK. Perangkat Kurikulum 2013 meliputi: Kurikulum Formal (mata pelajaran), Buku Penunjang, Rencana Persiapan Pembelajaran (RPP), Panduan Sistem Evaluasi, dan Materi Pendukung. Kebijakan dan regulasi tersebut tidak terdapat pada program BK. Program BK tidak memiliki kurikulum formal sebagaimana program pembelajaran.

Tahun 2016 Dirjen GTK menerbitkan Panduan Operasional Penyelenggaraan (POP) BK untuk jenjang SD, SMP, SMA, dan SMK. Berdasarkan POP BK tersebut, Kurikulum Formal Bimbingan\| atau standar kompetensi siswa tidak secara eksplisit tercantum didalamnya, sehingga guru BK mengalami kebingungan apa dan bagaimana mengembangkan kompetensi siswa di bidang akademik, pribadi, sosial, karier maupun spiritual-religiusitas siswa. Sementara dalam SP-BKK terdapat elemen isi (standar kompetensi siswa) yang merupakan satu dari empat elemen dalam SP-BKK. Elemen isi adalah standar kompetensi siswa yang hendak dikembangkan di setiap kelas dan jenjang sekolah. Standar kompetensi meliputi standar kompetensi akademik, pribadi-sosial, dan karier. Di Negara-negara bagian seperti Dakota, Conecticut, State of Utah mengembangkan elemen isi atau standar kompetensi tersebut mengacu pada model standar kompetensi yang dikembangkan oleh American School Counselor Asosiation (ASCA) tahun 2005. Standar kompetensi tersebut menjadi acuan dalam penyelenggaraan program BK, khususnya negara yang menganut sistem pendidikan 
barat, termasuk Indonesia. Namun standar kompetensi tersebut belum dikembangkan menjadi Kurikulum BK di sekolah Indonesia.

Legowo, dkk (2018) dalam penelitian tahun pertamanya telah mengembangkan lima standar kompetensi dasar serta indikator-indikatornya (Kurikulum formal\| bidang BK). Lima Standar kompetensi siswa yang dimaksud yaitu standar kompetensi akademik, pribadi, sosial, karir, dan religius-spiritualitas. Bilamana Kurikulum formal bidang BK ini digunakan sebagai dasar dalam pengembangan program BK di sekolah, maka program BK akan lebih berfungsi developmental (pengembangan) dan preventif (pencegahan) alih-alih fungsi kuratif (pengatasan) masalah.

Berdasarkan analisis situasi tersebut dapat disimpulkan bahwa program BK di sekolah baik di jenajang SMP maupun SMA saat sekarang ini lebih mendasarkan pada upaya-upaya pengatasan masalah alih alih mengembangkan potensi kepribadian (standar kompetensi siswa). Bilamana kondisi seperti ini terus berlanjut maka mind set pengawas, kepala sekolah, guru BK, para siswa, serta para stake holder di jenjang SMP dan SMA, bahkan masyarakat pada umumnya akan mempersepsi bahwa program BK berfungsi kuratif (menangani masalah-maslah) siswa saja alih-alih mengembangkan potensi dan standar kompetensi serta kepribadian siswa. Oleh sebab itu diperlukan upaya-upaya untuk mengubah mind set mereka melalui kegiatan workshop dan pendampingan pengembangan program BK berbasis standar kompetensi siswa.

\section{PEMBAHASAN}

Peran program bimbingan dan konseling di sekolah menjadi penting untuk diperhatikan. Rasional pentingnya program bimbingan dan konseling perlu disampaikan karena program bimbingan dan konseling merupakan mitra sejajar dengan program pendidikan lainnya. Berfokus pada pentingnya siswa memperoleh layanan bimbingan dan konseling oleh konselor sekolah, maka layanan bimbingan dan konseling yang komprehensif harus didasarkan pada tujuan sekolah, komunitas, dan negara. Pertimbangan pentingnya bimbingan dan konseling komprehensif diberikan ialah didasarkan pada perkembangan siswa, pengetahuan diri, pengambilan keputusan, merubah lingkungan, bantuan transisi dan berkaitan dengan pendidikan.

Secara teoretis, konsep program bimbingan dan konseling komprehensif tidak bisa dipisahkan dari dua sistem pendidikan utama yang saling berkaitan, yaitu adanya program instruksional (pembelajaran) serta program bimbingan dan konseling. Kedua komponen ini memiliki area penekanan yang berbeda dalam proses pengembangannya, program instruksional lebih menekankan pada pengembangan pelajaran dasar, persiapan pekerjaan, seni, karir, pendidikan teknis, ilmu pengetahuan, pendidikan jasmani, matematika, ilmu sosial, dan bahasa asing (Bahasa Inggris). Sedangkan dalam program bimbingan dan konseling lebih menekankan pada pengembangan dalam bidang akademik, bidang karir, dan bidang pribadi-sosial. Walaupun memiliki perbedaan dalam penekanan kompetensi yang dikembangkan, kedua komponen baik program instruksional maupun program bimbingan dan konseling saling mendukung dan saling berkaitan satu sama lain. Pada saat tertentu, program instruksional membutuhkan program bimbingan dan konseling dan di lain waktu program bimbingan dan konseling mendukung program instruksional.

Selanjutnya, kurikulum dimaknai sebagai berbagai hal (Guru, tenaga kependidikan, ruang kelas beserta perlengkapannya, penerangan, media belajar, sumber belajar, kamar mandi, kantin sekolah, lapangan olah raga dan, sarana prasarana, 
termasuk infrastruktur) yang semua tersebut bilamana memberikan dukungan terhadap ketercapaian tujuan pendidikan atau belajar dapat dikatakan itu adalah kurikulum.

Kurikulum juga dilihat dari pendekatan pengembangannya. Pertama pendekatan pengembangan kurikulum berbasis ilmu pengetahuan/ subject matter. Mata pelajaran dapat diartikan perumusan kurikulum didasarkan atas ilmu pengetahuan yang dipilih. Ilmu pengetahuan yang dipilih dioperasionalkan dalam proses pembelajaran dalam upaya mencapai tujuan pendidikan dan pelatihan tertentu, atau tujuan suatu lembaga sekolah pada jenjang pendidikan tertentu. Jika kurikulum diperuntukkan pada jenjang pedidikan SD, SMP, SMA atau SMK, maupun Perguruan Tinggi, maka ilmu pengetahuan yang berupa mata pelajaran/mata kuliah yang akan dipilih dan disajikan berdasarkan tujuan institusi setiap jenjang pendidikan tersebut. Kurikulum berbasis ilmu pengetahuan ini pernah diberlakukan di sekolah Indonesia pada era tahun 60-an.

Pendekatan yang lain, dalam pengembangan kurikulum didasarkan atas kompetensi (sikap, pengetahuan, dan keterampilan) yang diharapkan dikuasai peserta didik setelah menyelesaikan program pendididikan atau pelatihan dalam periode waktu tertentu. Kompetensi apa saja yang diharapkan untuk dikuasai oleh peserta didik selama dan setamat pendidikan tertentu dikonsepsikan sebagai pendekatan pengembangan kurikulum berbasis kompetensi. Berdasarkan rumusan-rumusan kompetensi yang ditetapkan agar dikuasai peserta didik, selanjutnya dicarikan sumber-sumber referensi ilmu pengetahuan yang relevan dan mendukungnya. Ilmu pengetahuan yang telah terkumpul dikategorikan ke dalam rumpun ilmu pengetahuan tertentu untuk selanjutnya diberikan simbol atau nama mata pelajaran atau mata kuliah tertentu disajikan sebagai pengalaman belajar peserta didik. Dengan pendekatan ini diharapkan peserta didik mengusai kompetensi yang diharapkan. Dewasa ini pengembangan kurikulum dengan pendekatan kompetensi diberlakukan diberbagai jenjang pendidikan formal maupun non formal.

Lensa pandang terhadap konsep kurikulum dapat pula dilihat dari stuktur hirarkisnya. konsep kurikulum secara hirarkhis ini sering digunakan dalam pengembangan suatu produk-produk pendidikan maupun pembelajaran. Ada lima konsep kurikulum yang disusun secara hirarkis yaitu kurikulum ideal, formal, perceive, operational, experiential, dan learned atau attained (Plomp dan Nieveen, 1997 ); Nieveen (Akker, dkk, 1999).

Kurikulum ideal (ideal curriculum) yaitu kurikulum yang berupa ide-ide, asumsi, visi, dan maksud yang akan mewarnai dokumen kurikulum. Sebagaimana dokumen kurikulum 2013 atau kurikulum KTSP dokumen kurikulumnya diwarnai oleh adanya ide-ide, asumsi, visi, dan tujuan pendidikan di setiap jenjang pendidikan, dan juga tujuan pendidikan nasional. Kedua kurikulum formal (Formal curriculum). Kurikulum ini berupa seperangkat dokumen mata pelajaran beserta kompetensi, silabus, materi belajar siswa dan panduan pembelajaran bagi guru dan yang sejenisnya. Dalam beberapa keperluan penelitian, kurikulum formal diistilahkan dengan 'Intended curriculum' yang mengacu pada kombinasi antara kurikulum ideal dan formal. Ketiga, Kurikulum yang dimaksud (percieved curriculum). Kurikulum ini merupakan representasi atas pemahaman dan interpretasi guru atau konselor atas dokumen kurikulum formal. Istilah lain kurikulum ini yaitu kurikulum instruksional.

Berdasarkan pemahaman guru atau konselor terhadap isi dokumen kurikulum formal, mereka selanjutnya menyusun Rencana Program Pembelajaran (RPP) atau Rencana Layanan Bimbingan Konseling (RLBK). Struktur isi RPP atau RLBK ini bervariasi namun secara umum memuat: (1) identitas mata pelajaran (nama mata 
pelajaran, topik/tema, kelas/ siswa, lama jam pelajaran); (2) Standar kompetensi, kompetensi dasar, dan indikator; (3) Materi Pembelajaran/ Layanan; (4) Sumber Belajar; (5) Metode dan Teknik; (6) Media dan Alat Bantu Pembelajaran; (7) Rencana Pelaksanaan Pembelajaran/Layanan (meliputi Pendahuluan, Inti, dan Evaluasi). Bila guru atau guru BK telah membuat RPP/ RLBK, maka selanjutnya siap untuk dioperasionalkan di dalam kelas oleh guru/konselor. Keempat, kurikulum operasional (operational curriculum). Kurikulum ini merepresentasikan proses pembelajaran yang diselenggarakan guru atau guru BK bersama peserta didik di dalam atau luar kelas sebagaimana yang direncanakannya. Kurikulum ini juga sering disebut sebagai kurikulum dalam tindakan (curriculum in act) dalam proses pembelajaran. Kelima, experential curriculum. Kurikulum ini mencerminkan kegiatan dimana para peserta didik mengalami proses pembelajaran yang diselenggarakan oleh guru/ konselor dalam periode waktu tertentu. Setiap siswa selama proses pembelajaran/ layanan bimbingan dan konseling mendapatkan pengalaman pembelajaran yang berbeda satu dengan yang lainnya meskipun mereka berada dalam ruang dan durasi waktu belajar yang sama. Namun mereka memiliki variabel atribut dengan intensitas dan potensi berbeda beda, maka pengalaman belajar yang mereka serap relatif berbeda pula.

Terakhir, attained/ learned curriculum. Kurikulum ini dimaknai sebagai hasil belajar yang dicapai peserta didik. Meskipun para peserta didik mengalami proses pembelajaran dalam durasi yang sama, sumber belajar yang sama, lingkungan belajar yang sama, namun mereka akan mendapatkan hasil belajar yang relatif berbeda. Kondisi capaian hasil yang berbeda inipun dipengaruhi oleh berbagai variabel atribut melekat atau yang mereka miliki berbeda. Konsepsi hirarkhi kurikulum sebagaimana diuraikan tersebut dapat digambarkan sebagai berikut.

\begin{tabular}{|c|}
\hline Ideal curriculum \\
\hline Formal curriculum \\
\hline Percieve curriculum \\
\hline Operational curriculum \\
\hline Experiential curriculum \\
\hline $\begin{array}{c}\text { Attained/learned } \\
\text { curriculum }\end{array}$ \\
\hline
\end{tabular}

Gambar 1.

Konsepsi Kurikulum Diadaptasi dari Nieveen dalam Akker, dkk (1999)

Komponen pembelajaran guru mata pelajaran telah nampak jelas tugas dan fungsinya dalam peyelenggaraan pembelajaran. Dukungan regulasi, dokumen kurikulum formalnya berikut manual dan petunjuk teknisnya telah tersedia lengkap untuk jenjang pendidikan SD, SMP, SMA, dan SMK, namun tidak demikian untuk komponen bimbingan dan konseling di Indonesia. Komponen program bimbingan dan konseling belum mendapat perhatian yang berarti dalam struktur kurikulum 2013 dan atau Kurikulum Tingkat Satuan Pendidikan (KTSP). Sebagai contoh, dihasilkan seperangkat dokumen kurikulum 2013 atau kurikulum KTSP oleh pemerintah terfokus pada komponen pembelajaran atau mata pelajaran. Kurikulum untuk mata pelajaran yang berbasis kompetensi ini telah dipersiapkan mulai dari proses pengembangan hingga implementasinya. Penyiapan para guru melalui diklat dan bimtek telah 
diselenggarakan secara masif dalam skala nasional. Tentu unuk maksud tersebut diperlukan dana yang sangat besar.

Komponen Program BK di sekolah belum memiliki kurikulum formal. Komponen sistem program BK tanpa adanya kurikulum formal bagaikan nahkoda kapal yang sedang berlabuh dengan kapalnya akan menuju kemana tidaklah jelas. Menurut nahkodanya yang penting berlabuh. Bilamana pada Kurikulum 2013 untuk komponen bimbingan dan konseling telah diterbitkan Panduan Opersional Penyelenggaraan (POP) BK SD, SMP, SMA dan SMK (Dirjen GTK, 2016), namun bila dicermati kurikulum formalnyapun belum di jumpai di dalamnya.

Ketiadaan kurikulum formal bimbingan dan konseling (BK) berdampak luas dalam hal penyelenggaraan program BK di sekolah, sebagaimana terjadi di Indonesia. Tiadanya kurikulum formal, tentu saja perceived curriculum (kurikulum yg dipahami) oleh para guru BK yang terrepresentasi dalam bentuk produk Satuan Layanan (SATLAN) BK sangat bervariasi khususnya tentang kompetensi siswa mana yang akan dikembangkan tidak jelas. Mereka cenderung akan mengembangkan kurikulum masing-masing sesuai pemahaman mereka atas kompetensi tugas perkembangan peserta didik yang akan dikembangkan. Pada gilirannya kurikulum operasional, eksperensial, dan kurikulum hasil atau yang dipelajari peserta didikpun sangat bervariasi antar guru BK satu dan yang lainnya, antar jenjang sekolah satu dan yang lainnya. Variasi tersebut dipengaruhi oleh tingkat pemahaman atas kompetensi peserta didik yang akan dikembangkannya.

Dampak yang lainnya, berkait dengan kebijakan setiap Kepala sekolah yaitu dalam mengambil keputusan tentang jam pelajaran (JP) bagi program layanan BK. Disuatu sekolah, kepala saekolah memberi kebijakan 2 jam pelajaran (JP) perminggu untuk penyelenggaraan program BK, di sekolah lainnya kepala sekolah hanya menetapkan 1 JP perminggu, di sekolah lainnya lagi tidak memberikan jam pemebelajaran (0 JP). Meskipun Dirjen GTK dalam Buku Pedoman Operasional Penyelenggaraan (POP) Bimbingan dan Konseling (BK) diberikan $2 \mathrm{JP} /$ minggu. Kondisi seperti ini, seolah-olah BK sebagai komponen pendidikan yang fungsi, tugas, peran dan tanggung jawabnya terhadap pencapaian tujuan lembaga sekolah dipersepsi tidak penting. Dalam Bahasa lain, bilamana penyelenggaraan pendidikan formal (sekolah) tanpa komponen BK-pun sekolah tetap dapat menjalankan visi, misi, tujuan dan programnya secara memadahi. Begitulah barangkali sikap dan persepsi sebagian kepala sekolah, guru, tenaga akademik, orang tua maupun masyarakat bahwa komponen BK dalam sitem pendidikan SD, SMP, SMA, dan SMK tidak penting. Kurikulum formal nampaknya menjadi kebutuhan yang sangat penting dan segera direalisaikan keberadanya.

\section{KESIMPULAN}

Berdasarkan dari pembahasan yang telah dipaparkan, maka dapat disimpulkan bahwa program dan kurikulum bimbingan dan konseling sangat penting untuk dikembangkan oleh konselor sekolah/guru Bimbingan dan Konseling. Melalui pendampingan yang dilakukan oleh para ahli di bidang bimbingan dan konseling maka akan terwujud suasana diskusi yang menarik dalam ruang akademik dengan bentuk workshop. 


\section{DAFTAR PUSTAKA}

American School Counselor Association (ASCA). (2005). ASCA national Model: A FrameWork for School Counseling Programs. Alexandria, VA: Author

Bogard J, M., Conner, C., Cocta, T,, Gregory, G, dan Ruffner, R. S. (2016). AlleganyLimestone Central Scholl K-12 Comprehensif Developmental School Counseling and Guidance Plan.

Fezler dan Brown. (2011). The Internasional Model for School Counseling Program,. 1'st Ed...: AASSA and U.S. State Departement Office of Overseas Schools

Fahrozin M., dkk. (2016). Pedoman Operasional Penelengaraan Bimbingan dan Konseling Sekolah Menengah Pertama. Jakarta: Kemendikbud, Dirjen GTK.

Fahrozin M., dkk. (2016). Pedoman Operasional Penelengaraan Bimbingan dan Konseling Sekolah Menengah Atas. Jakarta: Kemendikbud, Dirjen GTK.

Fahrozin M., dkk. (2016). Pedoman Operasional Penelengaraan Bimbingan dan Konseling Sekolah Menengah Kejuruan. Jakarta: Kemendikbud.

Legowo, E. , dkk (2018). Pengembangan Kurikulum Bidang Bimbingan di SMP berbasis Program Bimbingan dan KOnseling Komprehensif. Laporan Penelitian. Surakarta: LPPM UNS

Gysbers, N.C. \& Henderson, P. (2012). Developing \& Managing Your School Guidance \& Counseling Program (5th Ed.). Alexandria, VA: American Counseling Association.

Hatch, T. (2004).The ASCA National Model for school counseling programs, one vision, one voice for the profession. In Bradley T. Erford (Ed.) . Professional School Counseling: A Hand Book of Theories, Programs, and Practices, 2352247, Austin, Texas: CAPS Press.

Maine School Counselors In Cooperation with The Maine State Departement of Education. 2006. Mainne Comprehensive School Counseling Program K-12.

Naveh-Benjamin, J., McKeachie, W. J., Lin, Y., \& Tucker, D. G. (1986). Inferring students' cognitive structures and their development using the "ordered tree technique." Journal of Educational Psychology, 78, 130-140.

Richards, J.C. (2001). Curriculum Development in Language Teaching. The Edinburgh, England: Cambridge University Press.

Utah State Board of Education. (2016). College and Career Readiness Counseling Program Model. 2nd Ed. Salt Lake City 